\title{
APENDICECTOMIA PELAS TÉCNICAS DE LIGADURA SIMPLES E DE SEPULTAMENTO SEM LIGADURA DO COTO APENDICULAR. ESTUDO COMPARATIVO EM COELHOS
}

\author{
APPENDICECTOMY USING THE TIE-AND-DROP AND PURSE-STRING \\ TECHNIQUE WITHOUT LIGATION OF APPENDICULAR STUMP. \\ A COMPARATIVE STUDY IN RABBITS
}

\author{
Alfredo Soares Cabral Junior, ACBC-SP ${ }^{1}$ \\ Manuel de Jesus Simões ${ }^{2}$ \\ Saul Goldenberg, TCBC ${ }^{3}$ \\ Neil Ferreira Novo ${ }^{4}$ \\ Yara Juliano ${ }^{4}$ \\ Hélio Pereira Magalhães ${ }^{5}$
}

\begin{abstract}
RESUMO: Objetivo: Comparar as técnicas operatórias de ligadura simples (A) e de sepultamento sem ligadura do coto apendicular (B). Método: Foram utilizados 36 coelhos da linhagem Nova Zelândia, machos, distribuídos aleatoriamente em dois grupos de 18, divididos respectivamente em subgrupos de seis animais cada um e praticada a eutanásia decorrido o tempo pós-operatório de sete, 14 e 21 dias. Foram avaliados macroscopicamente conforme a ferida operatória estivesse limpa, tivessem abscesso ou deiscência e a cavidade abdominal pela presença de aderências peritoneais. Foi feita avaliação histológica pela presença ou ausência dos seguintes parâmetros: infiltrado inflamatório agudo e crônico, fibrose, granuloma de corpo estranho, necrose e integridade da camada mucosa. Resultados: Nos achados macroscópicos não foram observadas diferenças significantes no sétimo, $14^{\circ}$ e $21^{\circ}$ P.O. quanto à presença de abscesso e deiscência da ferida operatória entre os grupos A e B; o mesmo ocorreu quanto à presença de aderências peritoneais entre alças intestinais. Nos achados microscópicos houve diferença significante no $21^{\circ}$ P.O. quanto ao infiltrado inflamatório agudo maior no grupo $\mathrm{B}$, e à integridade da camada mucosa, maior no A. Na contagem de fibras colágenas houve diferença significante no $21^{\circ}$ P.O., maior no grupo B. Conclusão: Do ponto de vista histológico a técnica de ligadura simples é superior à de sepultamento sem ligadura do coto apendicular.
\end{abstract}

Descritores: Apendicectomia; Técnicas Operatórias; Coelhos.

\section{INTRODUÇÃO}

No tratamento do coto apendicular as três técnicas mais utilizadas são: a de ligadura simples ${ }^{1}$, a de sepultamento com ligadura ${ }^{2}$ e a de sepultamento sem ligadura ${ }^{3}$.
Ochsner e Lilly ${ }^{4}$, foram os principais defensores dessa técnica.

Atualmente, a ligadura simples encontra novos defensores pela simplicidade por via abdominal clássica e pelos cirurgiões que utilizam a videolaparoscopia ${ }^{5-9}$.

1. Mestre em Técnica Operatória e Cirurgia Experimental pela Universidade Federal de São Paulo - Escola Paulista de Medicina e Professor-Adjunto da Disciplina de Bases de Técnica Cirúrgica e de Anestesia - UNISA

2. Professor-Adjunto da Disciplina de Histologia e Biologia Estrutural da Universidade Federal de São Paulo - Escola Paulista de Medicina.

3. Professor Titular da Disciplina de Técnica Operatória e Cirurgia Experimental da Universidade Federal de São Paulo Escola Paulista de Medicina.

4. Professor-Adjunto da Disciplina de Bioestatística da Universidade Federal de São Paulo - Escola Paulista de Medicina e Professor Titular de Estudos de Saúde Coletiva - UNISA.

5. Professor Titular da Disciplina de Bases de Técnica Cirúrgica e de Anestesia - UNISA.

Recebido em 27/12/99

Aceito para publicação em 16/04/2001

Trabalho realizado na Disciplina Técnica Operatória e Cirurgia Experimental do Departamento de Cirurgia da Universidade Federal de São Paulo - Escola Paulista de Medicina e Disciplina de Técnica Cirúrgica e Bases de Anestesia da Faculdade de Medicina da Universidade de Santo Amaro - UNISA. 
Existem poucos estudos experimentais publicados sobre esse assunto. Kross ${ }^{10}$ estudou, comparativamente, em 39 coelhos, as técnicas de ligadura simples e a de sepultamento do coto previamente ligado; concluiu que a ligadura isolada foi o método mais simples, seguro e eficiente no tratamento do coto apendicular.

Yeager ${ }^{11}$ utilizou 44 coelhos divididos em três grupos: sepultamento do coto com e sem ligadura e ligadura simples, os resultados observados não mostraram uma superioridade entre as técnicas operatórias utilizadas.

Guimarães Neto ${ }^{12}$ utilizou 120 coelhos, adultos, comparando a técnica de ligadura simples e a de sepultamento do coto apendicular com ligadura na fase aguda do período pós-operatório (quatro a sete dias). Do ponto de vista da pressão de rotura e dos achados macroscópios não houve diferença entre as duas técnicas utilizadas. De acordo com o estudo histológico, entretanto, a técnica de ligadura simples mostrou-se superior à de ligadura com sepultamento do coto apendicular.

O objetivo deste trabalho foi comparar se a técnica operatória de ligadura simples é semelhante, melhor ou pior do que a do sepultamento sem ligadura.

\section{MÉTODO}

Foram utilizados 36 coelhos (Oryctolagus cuniculus), da linhagem Nova Zelândia, machos, com idade variando entre 45 a 60 dias, pesando em média $2.200 \mathrm{~g}$ fornecidos por criador filiado à Associação Paulista de Criadores de Coelhos.

Os animais foram distribuídos, aleatoriamente, em dois grupos de 18, denominados A e B. No Grupo A foi utilizada a técnica operatória de ligadura simples do apêndice vermiforme. No Grupo B foi utilizada a técnica de sutura em bolsa do ceco com sepultamento do coto apendicular sem ligadura. A seguir, cada um dos grupos foi dividido em subgrupos de seis animais cada um, segundo o tempo de evolução pósoperatória (P.O.) de sete, 14 e 21 dias.

Os animais foram mantidos em gaiolas individuais, em temperatura ambiente $\left(22^{\circ} \mathrm{C}\right)$, com ventilação adequada e livre acesso à água e à ração própria para a espécie.

Após período de adaptação de dez dias, os coelhos foram operados na sala do laboratório da Disciplina de Técnica Cirúrgica e Bases da Anestesia da Faculdade de Medicina da Universidade de Santo Amaro (UNISA).

Após jejum de 24 horas, com livre acesso à água, os animais foram submetidos a pré-anestesia com diazepam na dose de $5 \mathrm{mg} / \mathrm{kg}$ via intramuscular e, dez minutos após, anestesiados com solução de Quetamina na dose de $25 \mathrm{mg} / \mathrm{kg}$, sendo que até $50 \%$ da dose total foi feita inicialmente por via endovenosa na veia marginal da orelha. No decorrer da operação, se o animal apresentasse sinais de superficialização anestésica, o restante da dose de quetamina era dado em doses sucessivas, não ultrapassando, entretanto, a dose total prevista.

$\mathrm{O}$ acesso à cavidade abdominal, nos dois grupos, foi obtido através de laparotomia mediana de aproximadamente $5 \mathrm{~cm}$ de extensão. $\mathrm{O}$ apêndice vermiforme foi localizado pela porção distal do ceco e exteriorizado.
A artéria ileocólica foi inicialmente ligada na base do apêndice e o restante dos vasos do mesoapêndice ligado com fio de categute simples 5-0.

Nos animais do Grupo A, o apêndice vermiforme foi ligado com fio de poliglactina 910 5-0 por meio de ligadura simples, sem manuseio prévio nem utilização de pinça hemostática para evitar esmagamento. Após a ligadura, o apêndice foi seccionado com bisturi (lâmina 15). Após o término da apendicectomia, a extremidade do ceco foi reposicionada na cavidade peritoneal. $\mathrm{O}$ fechamento da parede abdominal foi realizado em dois planos: utilizou-se fio de polipropileno 5-0 englobando peritônio e músculo com sutura contínua ancorada alternadamente seguida de pontos simples na pele feitos com o mesmo fio.

Nos animais do Grupo B, após o isolamento do apêndice, foi feita sutura em bolsa na camada seromuscular da parede cecal, distante cerca de $1 \mathrm{~cm}$ da base apendicular com fio de poliglactina 910 5-0. Em seguida, foi colocada pinça hemostática (curva) e o coto apendicular sepultado após secção do apêndice.

O sepultamento do coto foi feito ao mesmo tempo em que a tração do fio completava o ajuste final da bolsa. Evitou-se deixar as alças intestinais expostas.

$\mathrm{O}$ fechamento abdominal foi realizado de maneira semelhante à utilizada no Grupo A, após o término da apendicectomia.

Os animais foram mortos (injeção endovenosa de metade da dose total de quetamina, seguida de injeção de $10 \mathrm{ml}$ de ar) decorrido o tempo pós-operatório programado para cada subgrupo.

A ferida operatória foi avaliada de acordo com a apresentação externa em: limpa, com deiscência ou presença de abscesso. A cavidade peritoneal foi cuidadosamente observada através de ampla incisão em forma de "U" pediculado $^{13}$, junto ao gradil costal, de acordo com os parâmetros previamente estabelecidos. Foi observada a presença ou não de aderência de alças na parte interna da parede abdominal e entre os diversos segmentos de alças de intestino delgado ou grosso, principalmente na região em torno da extremidade do ceco contendo o coto apendicular.

A seguir, a peça, contendo o coto apendicular, foi cuidadosamente retirada com o objetivo de dissecar suas aderências sem, no entanto, abrir a região pericecal, a fim de se preservar o coto apendicular. Retirada a peça, esta foi lavada em água corrente.

O estudo histológico foi realizado no Laboratório da Disciplina de Histologia e Biologia Estrutural da Universidade Federal de São Paulo/Escola Paulista de Medicina (UNIFESP-EPM).

O segmento da porção distal do ceco contendo o coto apendicular, após ser retirado, ficou mergulhado no líquido de Bouin durante 24 horas. Após este período de fixação, foram feitas trocas sucessivas com álcool a $70^{\circ} \mathrm{GL}$ progressivamente até $100^{\circ} \mathrm{GL}$.

A seguir, foram feitas secções longitudinais nas peças com o objetivo de atingir o ponto central do coto ligado (Grupo A) ou do sepultamento do coto (Grupo B), dividindo-as em dois fragmentos simétricos. 
As áreas correspondentes às alterações histológicas foram analisadas de acordo com a técnica operatória utilizada. Assim, para o Grupo A, as seguintes áreas foram analisadas:

1. parede do ceco proximal à ligadura;

2. parede interna do ceco (local da ligadura) e

3. local da ligadura (base apendicular).

No grupo B as áreas analisadas foram:

1. parede do ceco proximal à sutura em bolsa;

2. coto sepultado (parede externa);

3. coto sepultado (parede interna) e

4. local da sutura em bolsa.

A avaliação dos parâmetros histológicos obedeceu aos seguintes critérios:

Processo inflamatório agudo foi definido pela presença de congestão, edema e infiltrado por leucócitos polimorfonucleares [área 1 (Grupos A e B)]; processo inflamatório crônico foi definido pela presença de infiltrado de células mononucleares - linfócitos, plasmócitos ou histiócitos [área 1 (Grupos A e B)]; a fibrose foi definida pela identificação e concentração de fibras colágenas [áreas 1 e 3 (Grupo A) e áreas 1 e 4 (Grupo B)]; granuloma de corpo estranho cuja identificação foi feita pela presença de histiócitos e células gigantes fagocitando corpos estranhos [área 3 (Grupo A) e área 4 (Grupo B)]; a necrose foi identificada pela presença de restos celulares indefinidos e rodeados por infiltrado linfoplasmocitário [área 3 (Grupo A) e área 4 (Grupo B)]; a integridade da camada mucosa foi considerada quando estava preservada, sem erosão ou ulceração [área 2 (Grupo A) e área 3 (Grupo B)].

Para a contagem das fibras colágenas, utilizou-se a técnica de contagem de pontos ${ }^{14}$, com uma ocular de integração de 25 pontos, acoplada ao microscópio de luz com objetiva de 100X. Utilizou-se para leitura das áreas do coto apendicular [área 3 (Grupo A) e área 4 (Grupo B)], a conta- gem de 1.500 pontos. Somente foram incluídas as fibras colágenas que estavam localizadas nos pontos de interseção entre as linhas maiores e menores da ocular de integração, desprezando-se aqueles que estavam fora.

Para análise dos resultados, foram utilizados os seguintes testes estatísticos, que foram realizados na Disciplina de Bioestatística da Universidade Federal de São Paulo - Escola Paulista de Medicina: teste do qui-quadrado para tabelas $2 \times \mathrm{N}$ de Cochran ${ }^{15}$ com o objetivo de comparar os três períodos de eutanásia quanto à presença das variáveis consideradas. Este teste foi aplicado em separado para os Grupos A e B; teste exato de Fisher, ao infiltrado inflamatório agudo e à presença de integridade da mucosa, observada no $21^{\circ}$ dia do experimento, respectivamente; análise de variância por postos de KruskalWallis. Siegel ${ }^{16}$ e teste de Mann-Whitney para duas amostras independentes com a finalidade de comparar os Grupos A e B quanto às contagens de aderências e de fibras colágenas. Em todos os testes fixou-se em 0,05 ou $5 \%(\alpha \leq 0,05)$ o nível para rejeição de hipótese de nulidade, assinalando-se com um asterisco os valores significantes.

\section{RESULTADOS}

Quanto ao aspecto da ferida operatória, segundo a presença ou a ausência de abscesso não foram observadas diferenças estatisticamente significantes no sétimo, 14응 e 21으. P. entre os Grupos A e B, assim como quanto à presença ou à ausência de deiscência de ferida operatória nos mesmos períodos, em ambos os grupos.

Quanto aos achados da cavidade abdominal, segundo a presença de aderências peritoneais observada entre as alças intestinais (ileoileal; colocólica; ileocólica e região pericecal) no sétimo, 14으 e 21으. P.O. não houve diferenças estatisticamente significantes entre os Grupos A e B.

Tabela 1

Coelhos dos grupos A e B com a presença ou ausência de infiltrado inflamatório agudo na parede proximal do ceco. Resultado do teste do qui-quadrado $\left(\mathrm{x}^{2}\right)$ e do teste exato de Fisher (p).

\begin{tabular}{l|c|c|c|c|c|c|c|c|c}
\hline & \multicolumn{4}{|c|}{$\begin{array}{c}\text { Grupo A } \\
\text { Morte }\end{array}$} & \multicolumn{3}{|c|}{ Infiltrado Inflamatório Agudo } & \multicolumn{4}{c}{ Grupo B } & \\
\hline & Presente & Ausente & Total & \% Presença & Presente & Ausente & Total & $\%$ Presença & \\
\hline $7^{\mathrm{o}}$ & 6 & 0 & 6 & 100,0 & 6 & 0 & 6 & 100,0 & Dispensa análise \\
$14^{\mathrm{o}}$ & 6 & 0 & 6 & 100,0 & 6 & 0 & 6 & 100,0 & Dispensa análise \\
$21^{\circ}$ & 0 & 6 & 6 & 0,0 & 6 & 0 & 6 & 100,0 & $\begin{array}{l}\mathrm{P}=0,000 * \\
\mathrm{~A}<\mathrm{B}\end{array}$ \\
\hline Total & 12 & 6 & 18 & 66,7 & 18 & 0 & 18 & 100,0 & \\
\hline
\end{tabular}

$X^{2}$ calc. $=18,00 * X^{2}$ crit. $=5,99$

$21^{\circ}$ dia $<7^{\circ}$ e $14^{\circ}$ dias 
Tabela 2

Coelhos dos grupos A e B com a presença ou ausência da integridade da camada mucosa na área 2 do Grupo A e área 3 do Grupo B. Resultado do teste do qui-quadrado $\left(\mathrm{X}^{2}\right.$ crit. $\left.=5,99\right)$ e do teste exato de Fisher $(\mathrm{p})$.

\begin{tabular}{l|c|c|c|c|c|c|c|c|c}
\hline Morte & \multicolumn{4}{|c|}{ Grupo A } & \multicolumn{4}{c}{ Grupo B } & \\
\hline & Presente & Ausente & Total & \% Presença & Presente & Ausente & Total & $\%$ Presença & \\
\hline $7^{\circ}$ & 0 & 6 & 6 & 0,0 & 0 & 6 & 6 & 0,0 & Dispensa análise \\
$14^{\text {o }}$ & 0 & 6 & 6 & 0,0 & 0 & 6 & 6 & 0,0 & Dispensa análise \\
$21^{\circ}$ & 6 & 0 & 6 & 100,0 & 2 & 4 & 6 & 33,3 & $\begin{array}{l}\mathrm{P}=0,0303 * \\
\mathrm{~A}>\mathrm{B}\end{array}$ \\
\hline Total & 6 & 12 & 18 & 33,3 & 2 & 16 & 18 & 11,1 &
\end{tabular}

$\mathrm{X}^{2}$ calc. $=18,00^{*}$

$21^{\circ}$ dia $>7^{\circ}$ e $14^{\circ}$ dias

Somente no 21으. P. houve diferença estatisticamente significante entre os grupos A e B quanto ao infiltrado inflamatório agudo (Tabela 1). O mesmo pode ser observado quanto à presença ou à ausência de integridade da camada mucosa (Tabela 2).

Essas diferenças histológicas entre os grupos A e B podem ser ilustradas respectivamente, pelas Figuras 1 e 2 .

O Gráfico 1 não mostra diferença estatisticamente significante quanto à contagem de fibras colágenas entre os grupos A e B na área observada.

Pode-se observar diferença no 21으. P.O. entre os grupos conforme evidencia o Gráfico 2. Essas diferenças histológicas entre os grupos A e B podem ser observadas nas Figuras 3 e 4 , respectivamente.

\section{DISCUSSÃO}

A escolha das técnicas de ligadura simples e sepultamento do coto apendicular sem ligadura prévia, deveu-se ao fato de serem as duas técnicas operatórias utilizadas com freqüência no tratamento do coto apendicular ${ }^{17-25}$. Apesar

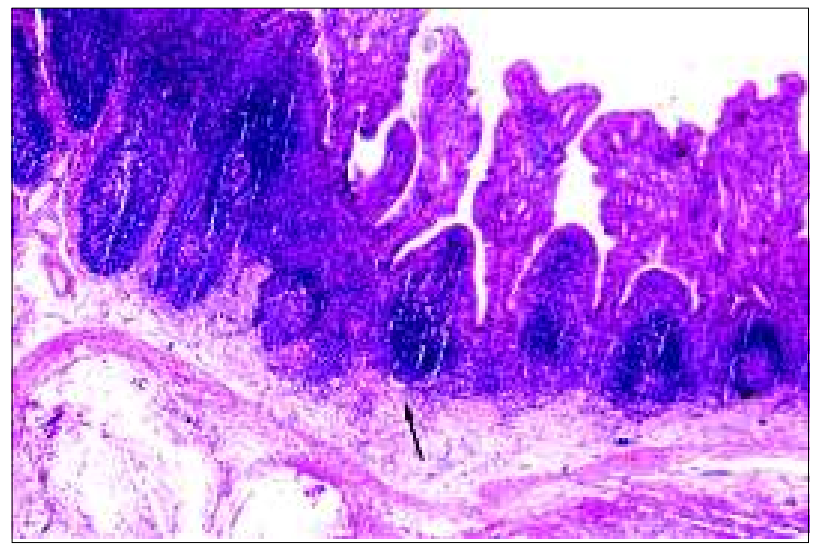

Figura 1 - Grupo A - 21 ${ }^{\circ}$ P.O.: nota-se na fotomicrografia a presença de integridade da camada mucosa (seta). disso, não existe ainda um consenso a respeito de qual das técnicas é a melhor, tanto do ponto de vista clínico ${ }^{26,27}$ quanto experimental ${ }^{28,29}$.

No presente trabalho optou-se por estudar a evolução da cicatrização do coto apendicular no sétimo, 14ㅇe e $21^{\circ}$ dias de P.O., porque nestes períodos os processos biológicos da resposta celular da cicatrização já estão bem caracterizados $^{30}$

Os achados neste trabalho, referentes à ferida operatória, são concordantes com os da literatura ${ }^{12,13}$ pois se mantiveram limpas na maioria dos coelhos não apresentando diferenças estatisticamente significantes.

Em relação às aderências, Kross ${ }^{10}$ observou que elas foram mais densas e numerosas quando o coto ligado foi sepultado do que as de ligadura simples. Guimarães Neto ${ }^{12}$ não notou superioridade entre as duas técnicas estudadas na fase aguda do período pós-operatório (quatro a sete dias). Putiatin ${ }^{28}$ sugeriu a modificação da técnica da apendicectomia da sutura em bolsa sem ligadura do coto apendicular, deixando-o o menor possível. Neste experimento, ocorreram aderências peritoneais em todos os animais estudados

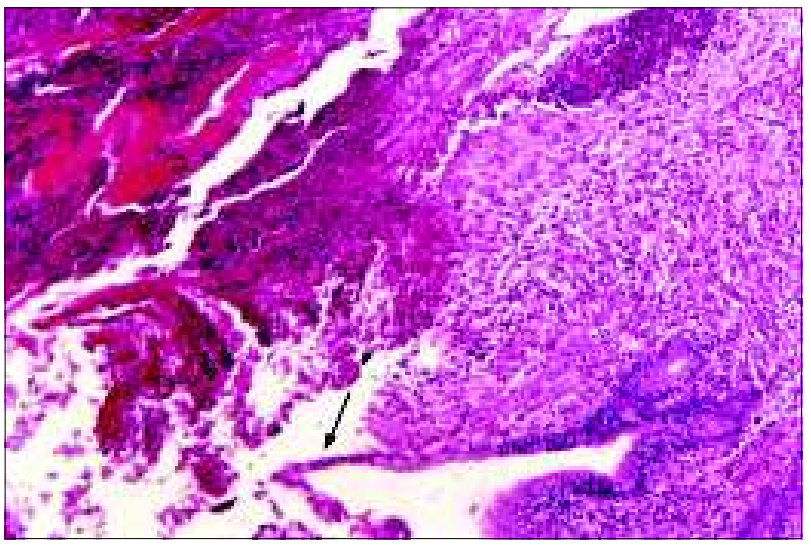

Figura 2 - Grupo B $-21^{\circ}$ P.O.: nota-se na fotomicrografia a ausência de integridade da camada mucosa (seta). 


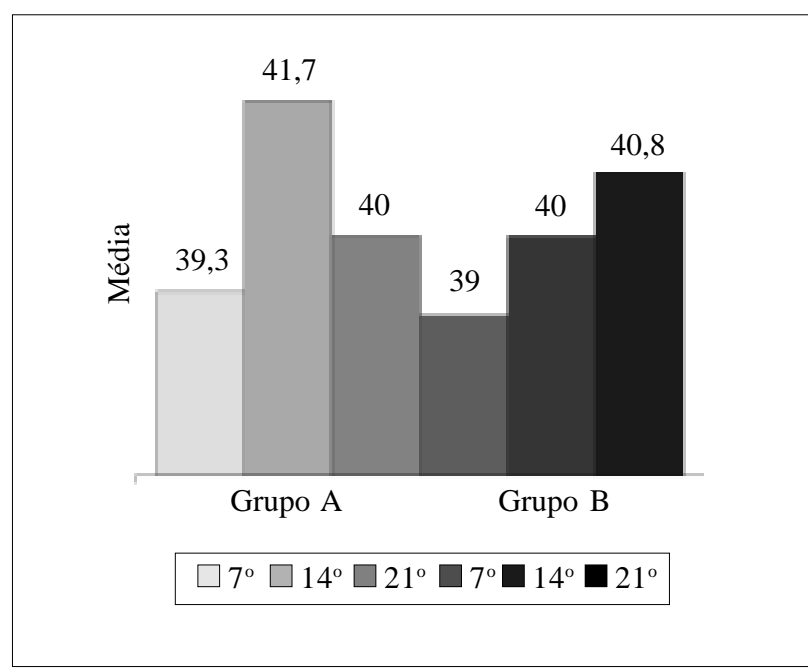

Gráfico 1 - Coelhos dos grupos A e B conforme a contagem de fibras colágenas na área 1 do Grupo A e área 1 do Grupo B.

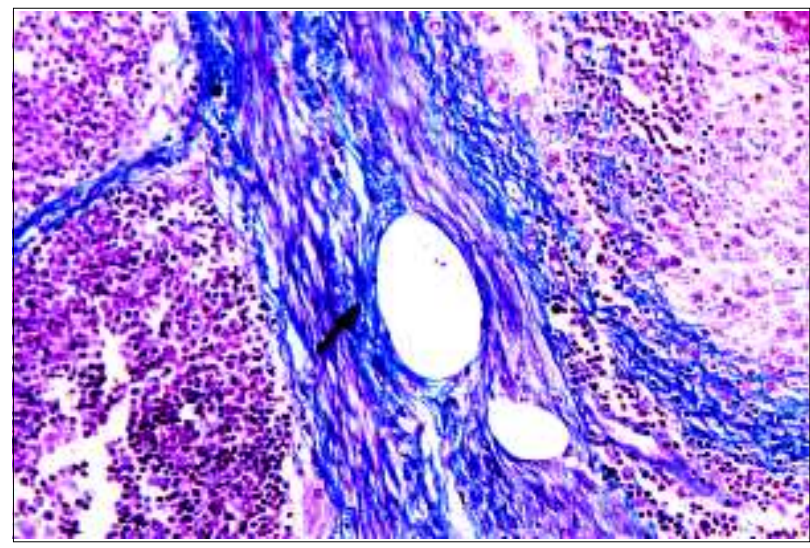

Figura 3 - Fotomicrografia mostrando fibras colágenas coradas pelo tricrômico de Masson (seta), no 21o de P.O. no Grupo A. (280x).

por ocasião do inventário da cavidade abdominal, nos três períodos observados, independentemente da técnica utilizada. Essas aderências foram sempre notadas na região do coto apendicular em todos os animais e, em outros, houve também aderências entre alças intestinais, não ocorrendo, todavia, diferença estatisticamente significante entre os dois grupos. É importante salientar que não houve complicações na cavidade peritoneal como abscesso, peritonite, deiscência e fistula cecal no coto apendicular nos animais estudados; houve entretanto, o aparecimento de bridas cecoileais de aproximadamente $2 \mathrm{~cm}$ de extensão no $21^{\mathrm{o}}$ P.O., em dois animais do grupo A e em três do grupo B, sendo, desses, dois no sétimo P.O., do ceco com a parede abdominal anterior e em um animal, no $21^{\circ}$ P.O., brida essa do coto apendicular até a raiz do mesentério de aproximadamente $4 \mathrm{~cm}$ de extensão. Porém, não poderíamos prever se num período de pós-operatório mais tardio ocorreria obstrução intestinal nesses animais.

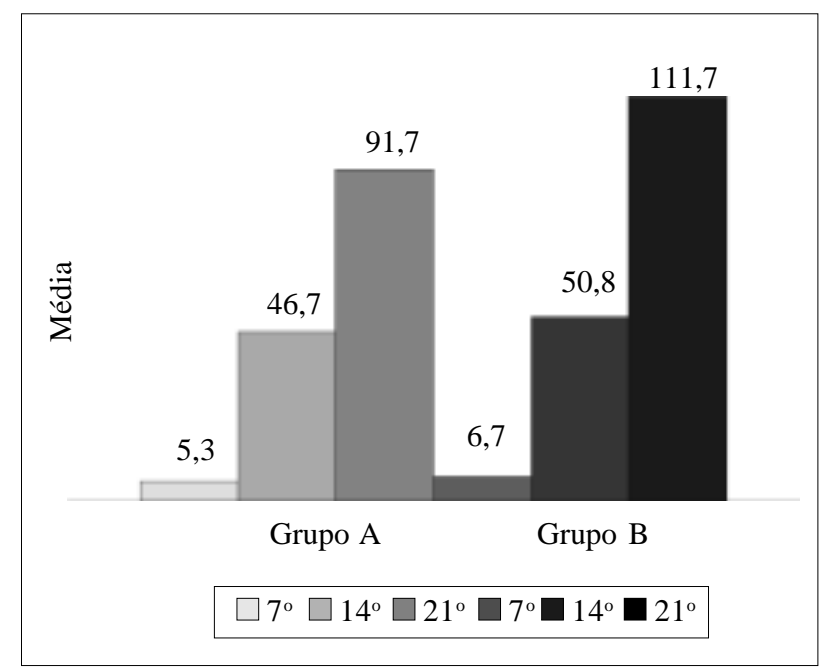

Gráfico 2 - Coelhos dos grupos A e B conforme a contagem de fibras colágenas (em 1.500 pontos) na área 3 do Grupo A e na área 4 do Grupo $B$.

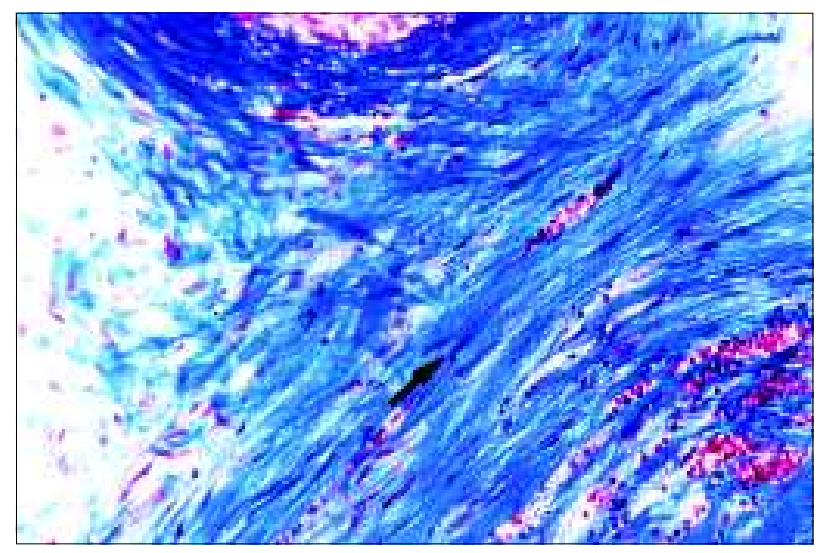

Figura 4 - Fotomicrografia mostrando aumento da densidade de fibras colágenas coradas pelo tricrômico de Masson (seta), no $21^{\circ}$ de P.O. no Grupo B. (280x).

Em relação aos achados histológicos referentes ao infiltrado inflamatório agudo, $\mathrm{Kross}^{10}$ notou que a reação inflamatória aguda foi mais acentuada na técnica de sepultamento do que na de ligadura simples. Yeager $^{11}$ observou que houve maior reação inflamatória aguda no ceco sepultado com ligadura prévia do que no grupo sem ligadura; o de ligadura simples foi o que apresentou menor ou nenhuma reação inflamatória aguda. Stadnik ${ }^{27}$ concluiu que a técnica de sutura em bolsa sem ligadura produziu reação inflamatória aguda menos acentuada, com desaparecimento mais rápido do que a de sutura em bolsa com ligadura. Guimarães Neto $^{12}$ observou que, na fase precoce no período pósoperatório, a parede adjacente proximal à ligadura do coto apendicular no grupo do sepultamento, o infiltrado inflamatório agudo esteve presente em $70 \%$ dos animais, enquanto que no de ligadura simples, em $30 \%$ no sétimo P.O. Neste estudo, em relação a esses achados 
histológicos (Tabela 1), a reação foi mais intensa quando se utilizou a sutura em bolsa sem ligadura, fato esse concordante com a maioria dos autores citados. Nesse grupo, observou-se, no $21^{\circ}$ P.O., a presença em todos os animais (100\%), enquanto no de ligadura simples em nenhum, sendo essa diferença estatisticamente significante e que pode ser atribuída à alteração isquêmica provocada pela sutura em bolsa.

Kross $^{10}$ e Yeager ${ }^{11}$, no estudo comparativo entre as técnicas de tratamento do coto apendicular, não fizeram menção de diferenças quanto aos achados histológicos relativos à presença de granuloma de corpo estranho, o mesmo ocorrendo neste estudo pois esteve presente em todos os animais independentemente do período observado.

Kross $^{10}$ e Yeager ${ }^{11}$ observaram necrose no tecido apendicular proximal à ligadura do coto e em parte da parede cecal com a técnica de sepultamento com ligadura do coto. Porém, no tecido apendicular proximal à ligadura, não observaram necrose com a técnica de ligadura simples do coto apendicular. Guimarães Neto ${ }^{12}$ observou resultados semelhantes quanto à necrose. Em relação ao coto apendicular a ocorrência associada à supuração foi uma constante em todos os animais submetidos às duas técnicas operatórias em ambos os períodos estudados, e, neste estudo, também esteve presente em todos os animais.

Quanto à integridade da camada mucosa, $\mathrm{Kross}^{10}$ observou sua alteração no grupo de coelhos em que foi utilizado sepultamento do coto com ligadura, e, em alguns animais, houve até completa perda de mucosa. No grupo de ligadura simples, a mucosa proximal à ligadura se manteve íntegra em todos os animais observados. Guimarães Neto ${ }^{12}$, observou que na camada mucosa, o número de camadas íntegras remanescentes, com a técnica de ligadura simples, foi maior no $4^{\circ}$ e no $7^{\circ}$ P.O. do que com a técnica de ligadura e sepultamento do coto apendicular. Esse resultado foi estatisticamente significante no 7o P.O., mostrando que a sutura em bolsa executada para obter uma segunda proteção promoveu um efeito deletério em vez de benéfico. No presente estudo, foi observado que, apesar de não haver diferença entre os dois grupos no $7^{\circ}$ e $14^{\circ}$ dia de P.O., houve diferença estatisticamente significante no 21ㅇ. P.O. (Tabela 2), pois a presença de camada mucosa íntegra no grupo da ligadura simples (Figura 1) foi maior do que a no grupo de sepultamento do coto apendicular sem ligadura (Figura 2), o que evidencia uma vantagem da técnica de ligadura simples do coto apendicular em preservar a integridade da camada mucosa.
Quanto à contagem de fibra colágena, Kross ${ }^{10} \mathrm{ob}-$ servou que a fibrose foi menos intensa no grupo de ligadura simples, quando comparada com a técnica de sepultamento do coto com ligadura. Yeager ${ }^{11}$ observou que a fibrose foi mais intensa nos grupos de sepultamento do coto e, quando este fora ligado, houve acentuado grau de fibrose, inclusive sobre a serosa; no sepultamento sem ligadura, o fenômeno foi intenso, porém menos acentuado do que no grupo com ligadura. No de ligadura simples houve pouca fibrose. Guimarães Neto ${ }^{12}$ observou que não houve diferença significante de fibrose entre os subgrupos e/ou períodos estudados na região da parede adjacente proximal à ligadura do coto

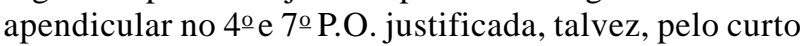
período de observação. No presente trabalho, em relação à contagem de fibras colágenas na área 1 do Grupo A com a mesma área do Grupo B não houve diferença estatisticamente significante nos dois grupos estudados (Gráfico 1). Todavia, em relação à histometria da fibra colágena nas áreas 3 do Grupo A e 4 do Grupo B (local da ligadura e sutura em bolsa, respectivamente), foi observado que houve, proporcionalmente aos períodos estudados, maior número de fibras colágenas no $21^{\circ}$ dia do que no $14^{\circ}$ e maior nesse do que no 7 o dia de P.O. (Gráfico 2). Entretanto, no $21^{\circ}$ P.O., o grupo B apresentou número de fibras colágenas significantemente maior do que o Grupo A (Figura 3). O fato de ter havido maior grau de fibrose na técnica de sepultamento sem ligadura do coto apendicular (Figura 4) do que na de ligadura simples, no 21ㅇ P.O., não demonstrou superioridade de uma técnica em relação à outra, uma vez que a fibrose é resultante de um processo de reparação tecidual. Entretanto, quando esta fibrose é em excesso pode tornar-se inconveniente pelo aparecimento de bridas que poderiam ocasionar obstrução intestinal; esse fato poderia ser esclarecido em seguimento pós-operatório mais tardio.

Conclui-se deste estudo que:

1. Em relação aos achados macroscópicos não há diferença entre as técnicas de ligadura simples e a de sutura em bolsa sem ligadura do coto apendicular em coelhos.

2. Quanto aos achados histológicos referentes à integridade da camada mucosa, a técnica de ligadura simples no $21^{\circ}$ P.O, é superior à de sepultamento do coto apendicular sem ligadura, pois preserva a integridade da camada mucosa do ceco.

3. Quanto à contagem de fibra colágena no $21^{\circ}$ P.O, a fibrose é maior na área de sutura em bolsa sem ligadura quando comparada à área de ligadura simples. 


\begin{abstract}
Background: The purpose of this study was to compare two surgical techniques: tie and drop(A) and purse string without ligation of apendicular stump.(B) Method: The study included 36 young male New Zealand inbred rabbits, randomly distributed into two groups of 18, divided into three subgroups of six each, when eutanasia was done after postoperative periods of 7, 14, and 21 days. The animals were macroscopically evaluated according to the wound presence of abscess or dehiscense, and the abdominal cavity was evaluated according to the presence of peritoneal adhesions. Histological evaluation was conducted according to the following parameters: acute and chronic inflammatory infiltration, fibrosis, foreign-body granuloma, necrosis and mucosal layer integrity. Results: No significants differences were found in the macroscopy studies in the postoperative periods of 7, 14 and 21 days, according to the wound presence of abscess or dehiscense; peritoneal adhesions presence were found in both techniques. As regards the histological findings in postoperative day 21, a difference on acute inflammatory infiltration, higher in group $B$, and the integrity of the mucosal layer, higher in group A were found. Counting of colagenous fibers in postoperative day 21 was significantly higher in group B. Conclusion: Regarding the histological findings, tie and drop technique is better than the purse string without ligation of apendicular stump.
\end{abstract}

Key Words: Appendicectomy; Surgical Techniques; Rabbits.

\title{
REFERÊNCIAS
}

1. Krönlein RU. Uëber die operative behandlung der acuten diffusen jauching-eiterigen peritonitis. Arch Klun Chir 1886; 33:507-24.

2. Treves F. Relapsing typhilitis treated by operation. Med Chir Trans 1888; 71:165-7.

3. Dawbarn R. A study in the technic of operation upon the appendix. Int J Surg 1895; 8:139-41.

4. Ochsner A, Lilly G. The technique of appendectomy: with particular reference to the treatment of the appendical stump. Surgery $1937 ; 2$ : 532-54.

5. Byrne DS, Bell G, Morrice JJ et al. Technique for laparoscopic appendicectomy. Br J Surg 1992; 79:574-5.

6. Desgroseilliers S, Fortin M, Lokanathan R et al. Laparoscopic appendectomy Versus open appendectomy: retrospective assessment of 200 patientes. Can J Surg 1995; 38:178-82.

8. Frazee RC, Bohannon WT. Laparoscopic appendectomy for complicated appendicitis. Arch Surg 1996; 131:50913.

9. Gangal HT, Gangal MH. Laparoscopic appendicectomy. Endoscopy 1989; 19: 127-9.

10a. Maldonado JC, Guidalevich A. Apendicectomia laparoscopia em pediatria. Rev Cir Infantil 1993; 3:66-7.

10. Kross I. The appendical stump: its manner of healing in the open and in the closed method of treatment. Arch Surg 1939; 39:1016-27.

11. Yeager GH. The appendiceal stump. Ann Surg 1947; 126: 814-9.

12. Guimarães Neto JG. Apendicectomia pelas técnicas de ligadura simples e de ligadura com sepultamento do coto apendicular: estudo comparativo em coelhos. São Paulo, 1996. 68p. [Tese Mestrado - Universidade Federal de São Paulo - Escola Paulista de Medicina].
13. Koh IHJ. Aderências peritoneais produzidas experimentalmente em ratos: estudo comparativo. São Paulo, 1987. 70 p. [Tese Mestrado-UNIFESP-EPM].

14. Weibel RR, Klister GS, Scherle WF. Practical stereological method for morfometrical citology. J Cell Biol 1966; 30: 23-8.

15. Cochran WG. Some methods for strengthening the common $\mathrm{X}^{2}$ test. Biometrics 1954; 10:417-451.

16. Siegel S, Castellani JR. Nonparametric statistics. $2^{\text {nd }}$ ed., N. York, Mac Graw Hill Int. Ed., 1988, 399 p.

17. Seelig MG. The treatment of the stump in appendicectomy: based on a pathologic and bacteriologic study of appendix. Ann Surg 1904; 40: 710-20.

18. Willis M. The treatment of the appendix stump after appendectomy. Ann Surg 1908; 48: 74-9.

19. Baldwin JF. The prevention of faecal fistula after appendectomy: simple ligation vs. precarious purse-string. Ann Surg 1932; 95: 704-14.

20. Sinha AP. Appendicectomy: an assessment of the advisability of stump invagination. Br J Surg 1977; 64: 499500.

21. Watters DAK, Walker MA, Abernethy BC. The appendix stump: should it be invaginated? Ann R Coll Surg Engl 1984; 66: 92-3.

22. Street D, Bodai BI, Owens LJ et al. Simple ligation vs. stump inversion in appendectomy. Arch Surg 1988; 123 : 689-90.

23. Osime U, Ofili OP, Duze A. A prospective randomized comparison of simple ligation and stump invagination during appendicectomy in Africans. JPMA J Pak Med Assoc 1988; 12:134-6.

24. Dass HP, Wilson SJ, Khan S et al. Appendicectomy stumps: "to bury or not to bury". Trop Doct 1989; 19: 108-9. 
25. Tugnoli G, Guidetti D, Bordone C et al. L'appendicectomia senza affondamento del moncone: una valida alternativa; nostra esperienza su 690 casi. Minerva Chir 1991; 46: 445-6.

26. Andrade JI, Sandoval EGB, Gomes CAP et al. Apendicectomia: tratament do coto apendicular por ligadura e por sepultamento. Rev Col Bras Cir 1994; 21:316-8.

27. Stadnik J, Kowalski W, Gruk M et al. Ocena róznych sposobów zaopatrywania kikuta wyrostka robaczkowego w'swietle badan dóswiadczalnych. Pol Przedgl Chir 1969; 41: 1054-8.

28. Putiatin SV. O profilaktike apaek posle appendektomii. Vestn Khir In. I.I. Grek 1978; 121(12): 39-43.

29. Koh IHJ, Kim YR, Crotti PLR et al. Estudo comparativo de duas técnicas operatórias para o tratamento cirúrgico do apêndice vermiforme: por secção e por invaginação: estudo experimental em coelhos: Oryctolagus cuniculus. Acta Cir Bras 1990; 5: 123-9.
30. Cabral Jr AS, Magalhães HP. Cicatrização das feridas operatórias. In: Magalhães HP - Técnica Cirúrgica e Cirurgia Experimental, $1^{\text {a }}$ ed. São Paulo, Sarvier, 1983, p. 191.

Endereço para correspondência:

Dr. Alfredo Soares Cabral Junior

Rua Manuel Pereira Guimarães, 350

04722-030 - São Paulo - SP 